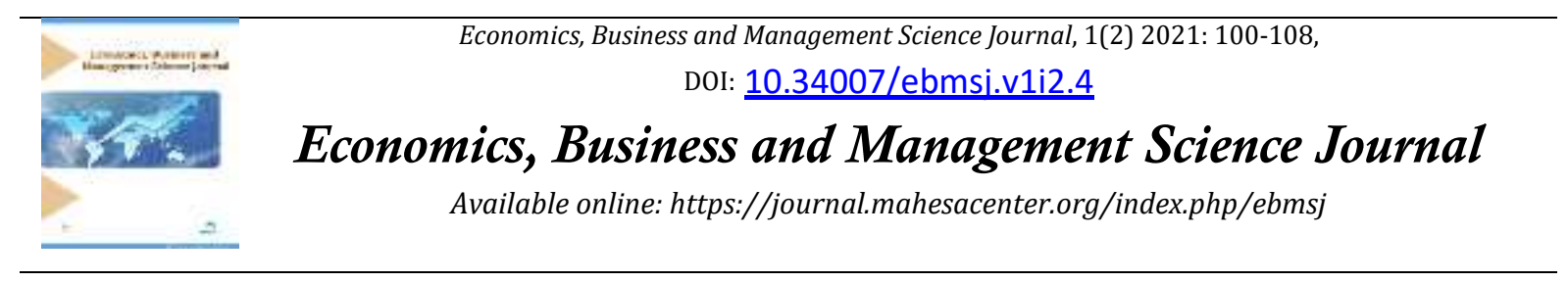

\title{
Diri dan Pengetahuan Terhadap Kinerja Pegawai Pada Dinas Pekerjaan Umum Medan
}

\section{Self and Knowledge of Employee Performance in Medan Public Works Office}

Yossy Suryandani Sitorus, Amrin Mulia Utama Nasution \& Tohap Parulian

Program Studi Manajemen Fakultas Ekonomi dan Bisnis, Universitas Medan Area Indonesia

\begin{abstract}
Abstrak
Tujuan penelitian ini adalah untuk mengetahui dan menganalisis pengaruh konsep diri dan pengetahuan terhadap kinerja pegawai pada Dinas Pekerjaan Umum Medan. Metode penelitian yang dilakukan adalah penelitian asosiatif, dimana variable diukur dengan skala likert. Metode pengumpulan data dengan wawancara, daftar pertanyaan dan pengamatan. Dalam penelitian ini sampel yang digunakan berjumlah 80 responden. Pengelolahan data menggunakan smartPLS3 dengan analisis Structural Equation Modeling (SEM). Hasil penelitian menunjukkan bahwa: (1) secara parsial variabel konsep diri mempengaruhi kinerja pegawai pada Dinas Pekerjaan Umum Medan sebesar 5,825 (2) secara parsial variabel pengetahuan mempengaruhi kinerja pegawai pada Dinas Pekerjaan Umum Medan sebesar 7,738. Nilai R-Square yang diperoleh sebesar 0,642. Untuk melihat besar pengaruh variabel bebas terhadap variabel terikat dengan cara menghitung koefisien determinasi menunjukkan bahwa sebesar 64,2\% sisanya 35,8\% dipengaruhi oleh faktor lain yang tidak dijelaskan dalam penelitian ini.
\end{abstract}

Kata Kunci: Konsep Diri; Pengetahuan; Kinerja.

\section{Abstract}

The purpose of this study was to determine and analyze the effect of self-concept and knowledge on employee performance at the Medan Public Works Department. The research method used is associative research, where variables are measured with a Likert scale. Data collection methods by interview, questionnaire and observation. In this study the sample used was 80 respondents. Data management uses smartPLS3 with Structural Equation Modeling (SEM) analysis. The results showed that: (1) partially the self-concept variable influenced the performance of employees in the Medan Public Works Department by 5,825 (2) partially the knowledge variable affected the performance of the employees at the Medan Public Works Department by 7,738. R-Square value obtained is 0.642. To see the effect of independent variables on the dependent variable by calculating the coefficient of determination shows that $64.2 \%$ the remaining $35.8 \%$ is influenced by other factors not explained in this study.

Keywords: Self-Concept; Knowledge; Performance.

How to Cite: Sitorus, Y.S. Nasution, A.M.U. \& Parulian, T. (2021). Diri dan Pengetahuan Terhadap Kinerja Pegawai Pada Dinas Pekerjaan Umum Medan. Economics, Business and Management Science Journal, 1(2) 2021: 100-108,

*E-mail: vossi12@gmail.com

ISSN 2550-1305 (Online) 


\section{PENDAHULUAN}

Pengertian kinerja atau performance emerupakan gambaran mengenai tingkat pencapaian pelaksanaan suatu program kegiatan atau kebijakan dalam mewujudkan sasaran, tujuan, visi dan misi organisasi yang dituangkan melalui perencanaan strategis suatu organisasi. Oleh karena itu, jika tanpa tujuan dan target yang ditetapkan dalam pengukuran, maka kinerja pada seseorang atau kinerja organisasi tidak mungkin dapat diketahui bila tidak ada tolak ukur keberhasilanya (Moeheriono, 2012:95). Kinerja setiap individu sangat berbeda dengan masing-masing individu lainnya sesuai dengan keterampilan, pengetahuan, pemahaman, umur, sikap, jenis kelamin, ,aupun kebutuhan yang dibawah seseorang kedalam situasi kerja. Kinerja setiap individu tidak akan sama karena setiap individu memiliki perbedaan pemahaman tentang kinerja. Untuk memberikan kesamaan kinerja maka pemimpin harus menetapkan standar atau pengukuran agar dapat dijadikan pedoman oleh setiap pegawai. (Sihaholo \& Utama, 2016; Ginting dkk, 2020).

Pengelolahan Sumber Daya Manusia suatu perusahaan juga sudah merupakan suatu tuntutan yang tidak dapat dielakan lagi. Para pengelola Sumber Daya Manusia dalam suatu perusahaan yang sering termasuk dalam divisi personalia harus dilakukan oleh orang-orang profesional, mengingat kegiatan personalia tersebut sudah semakin kompleks, mulai dari kegiatan perencanaan, rekrutmen dan proses seleksi serta pasar tenaga kerja internal, kompensasi, pelatihan hingga kegiatan pengawasan. Aktifitas-aktifitas dalam manajemen Sumber Daya Manusia ini memiliki hubungan yang positif terhadap peningkatan kinerja perusahaan. Kinerja suatu organisasi merupakan akumulasi kinerja semua individu yang bekerja disana. Disinilah Sumber Daya Manusia dibutuhkan dalam upaya mencapai tujuan organisasi. Pegawai yang melaksanakan kinerjanya secara efektif dan efisien hasilnya dapat mempengaruhi peningkatan prestasi kerja organisasi sehingga tujuan organisasi yang ditetapkan akan tercapai. (Lubis, 2016; Syahrial \& Robica, 2014).

Salah satu faktor yang mempengaruhi kinerja pegawai adalah deskripsi pekerjaan dan spesifikasi pekerjaan. Konsep diri merupakan hasil analisis pekerjaan sebagai rangkaian atau kegiatan proses menghimpun dan mengelola informasi mengenai pekerjaan, apabila deskripsi kurang jelas akan mengakibatkan seseorang kurang mengetahui tugas dan tanggung jawabnya terhadap pekerjaan itu, mengakibatkan pekerjaan tidak tercapai dengan baik. Dengan adanya perencanaan pekerjaan dan deskripsi tugas yang jelas, maka akan semakin produktif dan berprestasi sehingga keuntungan ekonomis. Selain itu kinerja pegawai memilki pengaruh terhadap konsep diri, maka dapat dinyatakan pula bahwa konsep diri pegawai tidak terlepas dari aspek mental atau emosi. Pegawai yang memiliki stabilitas emosional yang mantap dan terkendali akan cenderung memiliki konsep diri yang positif bila disbanding dengan pegawai yang tidak mampu mengendalikan emosi karenanya aspek emosi memegang peranan penting dalam membentuk dan mempengaruhi konsep diri pegawai. (Azmi \& Syahrial, 2016; Lubis, 2018).

Oleh karena itu untuk meningkatkan kinerja pegawai, maka banyak faktor yang perlu diperhatikan, namun dalam penelitian ini ditekankan pada variable yaitu pengetahuan. Pengetahuan menurut Sutrisno (2014:207) adalah informasi yang dimiliki seseorang untuk bidang tertentu. Pengetahuan merupakan kompetensi yang kompleks dan merupakan domain yang sangat penting dalam membentuk tindakan seseorang (Overt behavior).

Dari pengalaman terbukti bahwa perilaku yang didasari pengetahuan akan lebih langgeng dari pada perilaku yang tidak didasari dengan pengetahuan, karena dengan adanya pengetahuan yang dimiliki maka akan dapat meningkatkan kinerja melalui penyelesaian setiap tugas-tugas atau pekerjaan yang diberikan. Dari variabel ini yakni pengetahuan berkaitan karena dengan akumulasi pengetahuan dan pengalaman yang menyatu dalam diri seseorang maka akan menjadikan seseorang memiliki kompetensi yang tidak disadari dalam dirinya, atau akan terbentuk dalam sikap dan perilaku seseorang dalam menjalankan aktivitasnya sehari-hari. (Dalimunthe, 2018; Paningrum \& Usman, 2016).

\section{METODE PENELITIAN}

Jenis penelitian ini adalah asosiatif, menurut Sugiyono (2013:11), pendekatan asosiatif adalah pendekatan dengan menggunakan dua atau lebih variabel guna mengetahui hubungan atau pengaruh yang satu dengan yang lain. 
Populasi adalah wilayah generalisasi yang terdiri atas obyek/subyek yang mempunyai kualitas dan karakteristik tertentu yang ditetapkan oleh peneliti untuk dipelajari dan kemudian ditarik kesimpulannya (Sugiyono, 2009). Populasi dalam penelitian ini keseluruhan pegawai pada Kantor Dinas Pekerjaan Umum Medan adalah 100 orang. Dengan demikian, sampel adalah sebagian atau wakil populasi yang diteliti (Arikunto (2010:174). Sampel Penelitian ini melakukan perhitungan sampel dengan menggunakan rumus Slovin, tujuannya agar dapat ditentukan jumlah sampel yang representative yaitu :

$$
n=\frac{N}{1+N e^{2}}
$$

Dimana:

$n$ : jumlah sampel

$\mathrm{N}$ : jumlah populasi

e : batas toleransi kesalahan (error tolerance 5\%)

Pengambilan sampel yang masih dapat ditolerir yaitu $(0,05)$ maka jumlah sampel dapat dihitung sebagai berikut:

$$
\begin{aligned}
& N=\frac{100}{1+100 \cdot(0,05)^{2}} \\
& =\frac{100}{1+100 \cdot 0,0025}=\frac{100}{1+0,02}=\frac{100}{1,25}=80 \\
& \quad=80 \text { Responden }
\end{aligned}
$$

Hasil dari rumus Slovin menunjukkan pegawai di Kantor Dinas Pekerjaan Umum Medan yang akan dijadikan sampel terdapat 80 orang.

Tekhnik Analisis Data

1. Uji Instrumen Penelitian

Instrumen penelitian adalah merupakan alat ukur yang digunakan peneliti untuk mengumpulkan data dalam suatu penelitian (Sugiyono 2015:156). Dalam melakukan penelitian terhadap variabel-variabel yang akan diuji, pada setiap jawaban akan diberi skor.

2. Analisa data

Dalam penelitian ini analisis data menggunakan pendekatan Partial Least Square (PLS). PLS adalah model persamaan Structual Equation Modeling (SEM) yang berbasis komponen atau varian. Menurut Ghozali (2008), PLS merupakan pendekatan alternatif yang bergeser dari pendekatan SEM berbasis konvarian menjadi berbasis varian.
a. Model Struktural atau Inner Model
b. Model Pengukuran atau Outer Model 


\section{HASIL DAN PEMBAHASAN}

a. Uji Validitas

Validitas adalah suatu derajat ketepatan/kelayakan instrumen yang digunakan untuk mengukur apa yang akan diukur (Zainal Ariffin.2012).

Tabel 4.6

Uji Validitas / Convergent Validity

\begin{tabular}{|c|c|c|c|}
\hline & $\begin{array}{l}\text { Konsep Diri } \\
\left(\mathrm{X}_{1}\right)\end{array}$ & $\begin{array}{l}\text { Pengetahuan } \\
\left(\mathrm{X}_{2}\right)\end{array}$ & Kinerja (Y) \\
\hline $\mathrm{X}_{1.1}$ & 0,770 & & \\
\hline $\mathrm{X} 1.2$ & 0,823 & & \\
\hline $\mathrm{X} 1.3$ & 0,826 & & \\
\hline $\mathrm{X} 1.4$ & 0,098 & & \\
\hline $\mathrm{X} 2.1$ & & 0,792 & \\
\hline $\mathrm{X} 2.2$ & & 0,887 & \\
\hline $\mathrm{X} 2.3$ & & 0,880 & \\
\hline $\mathrm{X} 2.4$ & & 0,799 & \\
\hline $\mathrm{X}_{2.5}$ & & 0,798 & \\
\hline$Y_{1}$ & & & 0,767 \\
\hline $\mathrm{Y}_{2}$ & & & 0,856 \\
\hline $\mathrm{Y}_{3}$ & & & 0,861 \\
\hline $\mathrm{Y}_{4}$ & & & 0,850 \\
\hline $\mathrm{Y}_{5}$ & & & 0,784 \\
\hline
\end{tabular}

Hasil uji validitas menunjukkan bahwa semua indikator dari masing-masing variabel penelitian memiliki nilai outer loading $>0,5$ yang berarti dapat dikatakan valid.

b. Nilai Discriminant Validity

Table 4.7

Nilai discriminant validity

(Cross Loding)

\begin{tabular}{llll}
\hline & Konsep Diri $\left(\mathrm{X}_{1}\right)$ & $\begin{array}{l}\text { Pengetahuan } \\
(\mathrm{X} 2)\end{array}$ & Kinerja (Y) \\
\hline $\mathrm{X} 1.1$ & 0,770 & 0,411 & 0,597 \\
\hline $\mathrm{X} 1.2$ & 0,823 & 0,404 & 0,592 \\
\hline $\mathrm{X} 1.3$ & 0,826 & 0,443 & 0,479 \\
\hline $\mathrm{X} 1.4$ & 0,898 & 0,468 & 0,574 \\
\hline $\mathrm{X} 2.1$ & 0,400 & 0,792 & 0,461 \\
\hline $\mathrm{X} 2.2$ & 0,508 & 0,887 & 0,603 \\
\hline
\end{tabular}


Yossy Suryandani Sitorus, Amrin Mulia Utama. Nasution, \& Tohap Parulian, Diri dan Pengetahuan Terhadap Kinerja Pegawai Pada Dinas Pekerjaan Umum Medan

\begin{tabular}{llll}
\hline $\mathrm{X}_{2.3}$ & 0,420 & 0,880 & 0,547 \\
\hline $\mathrm{X} 2.4$ & 0,489 & 0,799 & 0,597 \\
\hline $\mathrm{X}_{2.5}$ & 0,349 & 0,798 & 0,707 \\
\hline $\mathrm{Y}_{1}$ & 0,548 & 0,786 & 0,765 \\
\hline $\mathrm{Y}_{2}$ & 0,511 & 0,609 & 0,856 \\
\hline $\mathrm{Y}_{3}$ & 0,596 & 0,464 & 0,862 \\
\hline $\mathrm{Y}_{4}$ & 0,595 & 0,485 & 0,850 \\
\hline $\mathrm{Y}_{5}$ & 0,553 & 0,535 & 0,785 \\
\hline
\end{tabular}

Hasil uji kesahihan pada masing-masing indikator memiliki nilai cross loading terbesar pada variabelnya dibandingkan dengan variabel lainnya. Berdasarkan hasil pengolahan tersebut maka dapat dikatakan semua indikator pada penelitian ini dikatakan valid. Selain menggunakan nilai outer loading, uji validitas pada Smart PLS, juga dapat dilakukan dengan melihat nilai AVE yang disajikan pada tabel berikut ini.

c. Nilai AVE

Tabel 4.8 Nilai AVE

(Average Varience Extracted)

\begin{tabular}{ll}
\hline Variabel & AVE \\
\hline Konsep Diri & o,689 \\
\hline Pengetahuan & o,693 \\
\hline Kinerja & o,68o \\
\hline
\end{tabular}

Dari table diatas dapat dilihat bahwa nilai AVE yang dihasilkan oleh semua indikator konstruk refleksif yaitu $>0,50$ untuk variable konsep diri (X1) sebesar 0,689, variabel pengetahuan (X2) sebesar 0,693 dan variable kinerja (Y) sebesar 0,680 sehingga dapat dikatakan valid.

d. Uji Reabilitas

Tabel 4.9 Uji Reliabilitas

\begin{tabular}{lll}
\hline Variable & $\begin{array}{l}\text { Composite } \\
\text { Reliability }\end{array}$ & Cronbachs Alpha \\
\hline Konsep Diri & 0,898 & 0,849 \\
\hline Pengetahuan & 0,918 & 0,889 \\
\hline Kinerja & 0,914 & 0,882 \\
\hline
\end{tabular}


Instrumen penelitian dikatakan reliabel jika memiliki nilai Alpha Crombach $>0.60$. Jika nilainya lebih kecil dari 0.60 maka kuesioner penelitian ini tidak reliabel.Hasil uji reliabilitas menunjukkan nilai Cronbach alpha dan composite Reability yang dihasilkan semua kontruks sangat baik yaitu $>0,60$ sehingga dapat disimpulkan bahwa semua indikator konstruk reflektif memenuhi uji reabilitas. Partial Least Square (PLS) dengan program SmartPLS 3.0.

e. Hasil Pengukuran Atau Outer Model

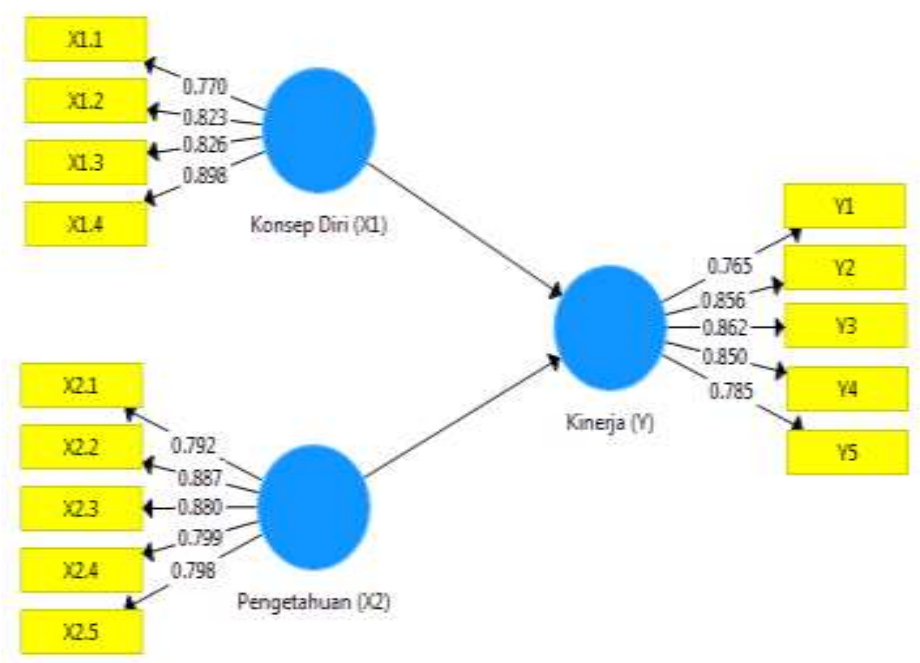

Gambar 4.2 Outer Model

Dari hasil outer model diperlihatkan bahwa untuk variable konsep diri (X1), variabel Pengetahuan (X2) dan variabel kinerja (Y) setiap indikatornya memiliki nilai outer loading lebih besar dari > 0,5 sehingga dapat dilakukan setiap indikator penelitian merupakan indikator yang valid.

f. Hasil Model Struktural Atau Inner Model

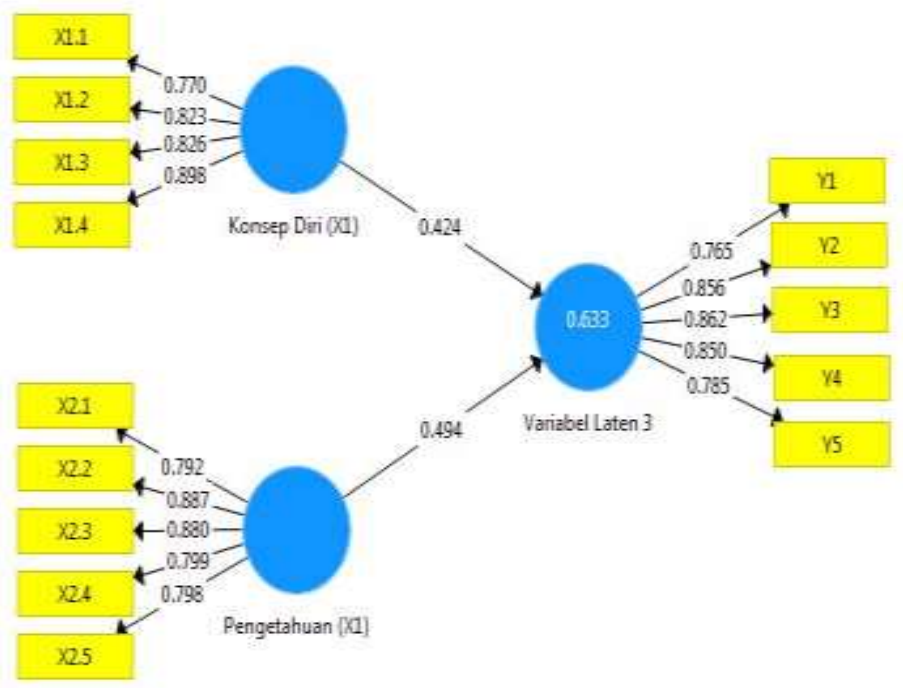




\section{Gambar 4.3 Inner Model}

Gambar diatas menunjukkan hasil inner model, dalam PLS inner model digunakan untuk menunjukkan pengaruh antar variabel penelitian. Dari hasil inner model dapat dilihat bahwa pengaruh variabel konsep diri terhadap kinerja pegawai adalah sebesar 0.424 dan pengaruh variabel pengetahuan terhadap kinerja pegawai adalah sebesar 0.494 .

g. Nilai R-Square

Tabel 4.10 Nilai $R$-Square

\begin{tabular}{lc}
\hline Variable & R-Square \\
\hline Konsep Diri $\left(\mathrm{X}_{1}\right)$ & \\
\hline Pengetahuan $\left(\mathrm{X}_{2}\right)$ & \\
\hline Kinerja $(\mathrm{Y})$ & 0,642 \\
\hline
\end{tabular}

R-Square bertujuan untuk melihat seberapa besar kemampuan variabel endogen (variabel yang dipengaruhi) dalam menjelaskan variabel eksogen (variabel yang mempengaruhi). Nilai R-square yang diharapkan adalah semakin mendekati 1, agar model penelitian dikatakan baik ( Joseph F. Hair, Hult, Ringle, \& Sardedt,2014). Berdasarkan Tabel 4.10 diketahui nilai RSquare untuk variabel kinerja pegawai sebesar 0,642 memiliki arti bahwa presentase besarnya kinerja pegawai yang dapat dijelaskan oleh kinerja pegawai adalah sebesar $64,2 \%$, sisanya sebesar $35,8 \%$ dijelaskan faktor lain di luar model yang diteliti.

T-Statistic

\section{Tabel 4.11 Koefisien Pengaruh dan T-Statistic}

\begin{tabular}{llllllll}
\hline & $\begin{array}{l}\text { Sampel } \\
\text { Asli (O) }\end{array}$ & $\begin{array}{l}\text { Rata-rata } \\
\text { sampel }\end{array}$ & $\begin{array}{l}\text { Standart } \\
\text { deviasi } \\
(\text { STDEV })\end{array}$ & $\begin{array}{l}\text { T Statistik } \\
\text { O/STDEV |) }\end{array}$ & P Values & Keputusan \\
\hline$\left(\mathrm{X}_{1}\right)->(\mathrm{Y})$ & 0,424 & 0,435 & 0,073 & 5,825 & 0,000 & Diterima \\
\hline$\left(\mathrm{X}_{2}\right)->(\mathrm{Y})$ & 0,494 & 0,491 & 0,064 & 7,738 & 0,000 & Diterima \\
\hline
\end{tabular}

Berdasarkan sajian data pada tabel di atas, dapat diketahui bahwa dari tiga hipotesis yang diajukan dalam penelitian ini, semua hipotesis diterima karena masing-masing pengaruh yang ditunjukkan memiliki nilai yaitu:

1. Hipotesis 1 Koefisien pengaruh konsep diri terhadap kinerja pegawai yaitu sebesar 0,424 dengan nilai t-statistic 5,825 > t-tabel 1,99. Hasil ini menunjukkan bahwa terdapat pengaruh yang signifikan antara konsep diri terhadap kinerja pegawai Dinas Pekerjaan Umum Medan. Berdasarkan hasil ini H1 dapat dinyatakan diterima. Nilai pvalue pada kolom sig $0.000<0,05$ artinya signifikan. Hal ini menjelaskan bahwa 
konsep diri berpengaruh positif dan signifikan terhadap kinerja pegawai Dinas Pekerjaan Umum Medan.

2. Hipotesis 2 Koefisien pengaruh pengetahua terhadap kinerja pegawai yaitu sebesar 0,494 dengan nilai T-statistic 7,738 > t-tabel 1,99. Hasil ini menunjukkan bahwa terdapat pengaruh yang signifikan antara pengetahuan terhadap kinerja pegawai Dinas Pekerjaan Umum Medan. Berdasarkan hasil ini H2 dapat dinyatakan diterima. Nilai p-value pada kolom sig $0.000<0,05$ artinya signifikan. Hal ini menjelaskan bahwa konsep diri berpengaruh positif dan signifikan terhadap kinerja pegawai Dinas Pekerjaan Umum Medan.

\section{Pengaruh Konsep Diri Terhadap Kinerja Pegawai}

Hasil pengujian hipotesis (H1) telah membuktikan terdapat pengaruh antara konsep diri terhadap kinerja pegawai pada Dinas Pekerjaan Umum Medan sebesar 0.424 , melalui hasil perhitungan yang telah dilakukan diperoleh nilai t-statistic adalah 5,825 dan $t_{\text {tabel }} 1.99$ sehingga tstatistic $>\mathrm{t}$ hitung $(5,825>1.99)$. Nilai $p$-value pada kolom sig 0,000 $<0,05$ artinya signifikan. Sehingga dapat disimpulkan bahwa variabel konsep diri berpengaruh positif terhadap kinerja pegawai.

\section{Pengaruh Pengetahuan Terhadap Kinerja}

Hasil pengujian hipotesis (H2) telah membuktikan terdapat pengaruh antara pengetahuan terhadap kinerja pegawai pada Dinas Pekerjaan Umum Medan sebesar 0.494 , melalui hasil perhitungan yang telah dilakukan diperoleh nilai t-statistic adalah 7,738 dan t tabel 1.99 sehingga $\mathrm{t}$-statstic $>\mathrm{t}$ hitung $(7,738>1.99)$. Nilai $\mathrm{p}$-value pada kolom sig $0,000<0,05$ artinya signifikan. Sehingga dapat disimpulkan bahwa variabel pengetahuan berpengaruh positif terhadap kinerja pegawai.

\section{SIMPULAN}

Berdasarkan hasil analisis yang telah dibahas pada bab terdahulu, maka dapat ditarik kesimpulan sebagai berikut:

1. Dapat disimpulkan bahwa konsep diri berpengaruh positif dan signifikan terhadap kinerja pegawai pada Dinas Pekerjaan Umum Medan.

2. Dapat disimpulkan bahwa pengetahuan berpengaruh positif dan signifikan terhadap kinerja pegawai pada Dinas Pekerjaan Umum Medan

\section{DAFTAR PUSTAKA}

Arikunto, Suharsimi. (2010). Prosedur Penelitian Suatu pendekatan Praktek. Jakarta: Rineka Cipta

Azmi, N., \& Syahrial, H. (2016). PENGARUH KOMUNIKASI YANG EFEKTIF DAN MOTIVASI KERJA TERHADAP KINERJA KARYAWAN PADA PT LANGKAT NUSANTARA KEPONG KANTOR KEBUN GOHOR LAMA. $\begin{array}{lllll}\text { JKBM } \quad \text { KONSEP BISNIS } & \text { DAN }\end{array}$ doi:https://doi.org/10.31289/jkbm.v3i1.238

Br. Ginting, S., Effendi, I., \& Amelia, W. (2020). PENGARUH SERVICE DAN PROMOSI TERHADAP KEPUASAN NASABAH PADA TRUST SEBAGAI VARIABEL INTERVENING DI BPR LAKSANA ABADI SUNGGAL. Jurnal Ilmiah Manajemen dan Bisnis (JIMBI), 1(2).

Dalimunthe, H. (2018). Pengaruh Gaya Kepemimpinan dan Motivasi Kerja terhadap Kinerja Karyawan Usaha Pembungkusan Garam Konsumsi. JKBM (JURNAL KONSEP BISNIS DAN MANAJEMEN), 5(1), 53-62. doi:https://doi.org/10.31289/jkbm.v5i1.1790

Fahrun Nisa,. (2014). Pengaruh Pengetahuan, Keterampilan, Konsep Diri Dan Karakteristik Pribadi Terhadap Kinerja Staf Pada Smk N Kota Pekalongan. Jurnal Ekonomi Dan Bisnis.

Ghozali, I. (2008). Structural Equation Modeling. Metode Alternatif dengan Partial Least Square, Edisi 2. Bahan Penerbit Universitas Diponegoro: Semarang. 
Yossy Suryandani Sitorus, Amrin Mulia Utama. Nasution, \& Tohap Parulian, Diri dan Pengetahuan

Terhadap Kinerja Pegawai Pada Dinas Pekerjaan Umum Medan

Lubis, A. (2016). PENGARUH KOMUNIKASI DAN MANAJEMEN HUBUNGAN KARYAWAN TERHADAP KINERJA KARYAWAN PADA PT. BANK PANIN DUBAI SYARIAH CABANG MEDAN. JKBM (JURNAL KONSEP BISNIS DAN MANAJEMEN), 3(1). doi:https://doi.org/10.31289/jkbm.v3i1.233

Lubis, A. (2018). "Pengaruh Adversity Quotient Terhadap Kinerja Karyawan Melalui Motivasi Kerja Sebagai Variabel Intervening ("Studi Pada Pengemudi Taksi Konvensional di Kota Medan)”. JKBM (JURNAL KONSEP BISNIS DAN MANAJEMEN), 4(2). doi:https://doi.org/10.31289/jkbm.v4i2.1525

Moeheriono. (2012). Pengukuran Kinerja Berbasis Kompetensi. Jakarta: Raja Grafindo Persada.

Oktaviani,Rina. (2015). Pengaruh Kecerdasan Emotional, Konsep Diri, Motivasi Terhadap Kinerja Dosen Universitas Bina Darma Palembang. Universitas Bina Darma, Palembang

Paningrum, R., \& Usman, A. (2016). IMPLEMENTASI GOOD CORPORATE GOVERNANCE (GCG) DALAM MENINGKATKAN KINERJA KEUANGAN PADA PT. PERUSAHAAN GAS NEGARA (PGN) Tbk. MEDAN. JURNAL AKUNTANSI DAN BISNIS : Jurnal Program Studi Akuntansi, 2(1). doi:https://doi.org/10.31289/jab.v2i1.1721

Serlin Serang, Alias. 2018. Pengaruh Pengetahuan, Sikap Kerja Dan Pengalaman Kerja Terhadap Kinerja Karyawan pada Kantor BPJS Ketenagakerjaan Cabang Makassar. Jurnal Ilmu Ekonomi Volume 1 Nomor 1 (2018) Oktober

Sihaloho, S., \& Utama, A. (2016). PENGARUH STRATEGI PROMOSI TERHADAP KEPUTUSAN PEMBELIAN KONSUMEN PADA CARREFOUR CITRA GARDEN MEDAN. JURNAL AKUNTANSI DAN BISNIS : Jurnal Program Studi Akuntansi, 2(2). doi:https://doi.org/10.31289/jab.v2i2.249

Sugiyono (2015). Metode Penelitian Kombinasi (Mix Methods). Bandung: Alfabeta

Sugiyono, (2009). Metode Penelitian Pendidikan (Pendekatan kuantitatif, kualitatif dan R\&D). Bandung: Alfabeta.

Sugiyono. (2012). Memahami Penelitian Kualitatif". Bandung : alfabeta.

Sutrisno, Edy. (2014). Manajemen Sumber Daya Manusia. Cetakan Keenam. Penerbit : Kencana, Jakarta.

Syahrial, H., \& Robica, D. (2014). ANALISIS PENGARUH STRES KERJA TERHADAP KINERJA DENGAN KEPUASAN KERJA SEBAGAI VARIABEL INTERVINIG PADA PT.PERUSAHAAN GAS NEGARA (PERSERO) MEDAN. JKBM (JURNAL KONSEP BISNIS DAN MANAJEMEN), 1(1), 43-49. doi:https://doi.org/10.31289/jkbm.v1i1.1400

Zainal,Arifin. (2012). Penenlitian Pendidikan Metode dan Paradigma Baru. Bandung: Remaja Rosda Karya 